\title{
Blood Lipid Levels in Patients with Osteopenia and Osteoporosis: A Systematic Review and Meta-Analysis
}

\section{Hang Zhao}

hebei genral hospital

An Song

Hebei General Hospital

Yong Li

Hebei General Hospital

Licui Qi

Hebei General Hospital

\section{Chong Zheng}

Shijiazhuang third hospital

\section{Luping Ren}

Hebei General Hospital

Guangyao Song ( $\nabla$ guangyaosong123@163.com )

Research

Keywords: Osteopenia, Osteoporosis, Lipids

Posted Date: May 20th, 2020

DOI: https://doi.org/10.21203/rs.3.rs-26729/v1

License: (a) (i) This work is licensed under a Creative Commons Attribution 4.0 International License. Read Full License 


\section{Abstract}

Background: Considering the controversial relationship between blood lipid levels and osteopenia and osteoporosis (OP), we performed this meta-analysis.

Methods: Using specific keywords and related words, we searched PubMed, Embase, and Cochrane Library databases. The NewcastleOttawa Scale form was used to evaluate the quality of the literature. According to the inclusion and exclusion criteria, we systematically screened the literature to extract relevant information and data. Revman 5.3 and Stata 13.0 software were used for statistical analysis. Results were expressed as the mean difference and $95 \%$ confidence interval. The heterogeneity test was conducted according to $\mathrm{I}^{2}$ and $\mathrm{Q}$ tests. Egger's test was used to quantitatively evaluate publication bias.

Results: This analysis involved 12 studies and included 12,395 subjects. The quality of the literature was acceptable. Among subjects who were not taking lipid-lowering drugs, total cholesterol (TC), triglycerides (TG), and low-density lipoprotein cholesterol (LDL-C) in the osteopenia were not significantly increased/decreased. There were no significant differences in LDL-C in postmenopausal women in osteopenia. TG was unchanged in the OP group in subjects without taking lipid-lowering drugs. HDL-C was elevated in OP group but not in osteopenia group in all subjects

Conclusions: HDL-C was elevated in patients with OP.

\section{Background}

Osteoporosis (OP) is a disease characterized by reduced bone mineral density (BMD) and an increased risk of osteoporotic fractures. It is one of the most common metabolic diseases in the elderly population. This poses a serious health concern worldwide ${ }^{[1]}$ because osteoporotic fractures are the leading cause of disability and death in elderly patients ${ }^{[2]}$. The onset of this disease is associated with various factors, including aging, gender, insufficient calcium intake, vitamin D deficiency, low body mass index (BMI), decreased physical activity ${ }^{[3]}$, and hyperthyroidism ${ }^{[4]}$. Among them, nutrition is one of the most important factors. When malnutrition occurs, the raw materials for bone formation are limited, which can lead to the development of osteopenia and even OP. BMI is an indicator used to assess nutritional status. Previous studies have shown that people with a high BMI have a low risk of OP[5]. It has been suggested that blood lipid levels also reflect the nutrition level to some extent, but in patients with osteopenia or OP, the results of various studies on blood lipid levels have been inconclusive. Gu et al ${ }^{[6]}$ found that compared with the control group, total cholesterol (TC) and low-density lipoprotein cholesterol (LDL-C) were significantly increased in adult patients with osteopenia and OP. Ersoy's $\mathrm{s}^{[7]}$ study indicated that TC and LDL-C were decreased in postmenopausal women with OP. However, $\mathrm{Li}{ }^{[8]}$ found that $\mathrm{TC}$, triglyceride (TG), and LDL-C levels were not significantly different in postmenopausal women with OP. Therefore, the blood lipid levels in patients with osteopenia, or OP remain unknown. In addition, whether an increase in blood lipid levels can protect patients from the development of OP is not well understood. The aim of this meta-analysis was to extract blood lipid indicators in patients with osteopenia, or OP from case-control studies and to determine their levels.

\section{Methods}

\subsection{Search strategy}

Two researchers used subject words and free words, including "bone mineral density", "osteoporosis", "fractures", "bone", and "lipids", to search PubMed, Embase, and Cochrane databases (Supplementary material 1). We also manually checked the references listed in the retrieved references to prevent missing studies. The search was limited to English language and deadline was February 2020. For articles with only titles and abstracts, we requested articles by email. The inclusion and exclusion criteria were as follows.

\subsection{Inclusion criteria}

i) The article involved at least one of osteopenia and osteoporosis, and the diagnostic criteria were clear.

ii) The article involved at least one of the following blood lipids: TC, TG, high-density lipoprotein cholesterol (HDL-C), or LDL-C.

iii) The study was a case-control study.

iv) The literature provided original data or relevant data that could be obtained based on data conversion. 


\subsection{Exclusion criteria}

i) The subjects had acute cardiovascular/cerebrovascular diseases or malignant tumors.

ii) Subjects with diseases which may affect bone metabolism or calcium absorption, such as serious malabsorption syndrome, enteritidis, hyperparathyroidism, chronic infectious arthritis, osteomalacia and diabetes.

iii) Subjects receiving medications such as glucocorticoid, estrogen, androgen, calcitonin, and antidiabetic agents.

iv) The diagnosis of osteopenia and osteoporosis was not clear.

v) The data were incomplete or could not be obtained by conversion.

vi) The study was a review, case report, commentary, or animal/cell-based.

\subsection{Literature screening}

Two researchers independently screened the literature according to the inclusion and exclusion criteria and then compared their findings with each other. First, duplicate studies, animal/cell experiments, case reports, and commentaries were removed. Second, the studies were screened based on their title and abstract. Last, the full text was read to decide whether the study should be included. If there were objections, the studies were discussed with a third party to decide whether to include them.

\subsection{Information extraction}

We read the full text of each study and extracted the relevant information, which included the name of the first author, publication year, country the studied was performed in, the average age of subjects, the sex of patients and lipid-lowering drugs. In addition, the occurrence of osteopenia or OP, and the differences in blood lipid levels between different groups were extracted.

\subsection{Quality assessment}

The quality of the literature included was evaluated according to the Newcastle-Ottawa Scale (NOS) form. A score of 1-3 points was considered poor quality, 4-6 points indicated moderate quality, and a score of 7-9 points was considered high quality. The specific scoring criteria were as follows: Selection (adequate case definition, case representativeness, selection of controls, definition of controls), Comparability (comparability of cases and controls based on the design or analysis), and Exposure (ascertainment of exposure, same method of ascertainment for cases and controls, non-response rate) (Supplementary material 2).

\subsection{Statistical analysis}

The meta-analysis was performed using Revman 5.3 and Stata 13.0 software. All blood lipid indicators were considered continuous variables, and the effect amount was shown as the mean difference (MD) and $95 \%$ confidence interval $(95 \% \mathrm{Cl})$. An inverse variance model was used as the statistical model. Heterogeneity analysis was performed by $Q$ and $\mathrm{I}^{2}$ tests. If $\mathrm{P}>0.1$ in the $Q$ test or $\mathrm{I}^{2}<50 \%$ in the $\mathrm{I}^{2}$ test, it was considered homogeneous. If $\mathrm{P}<0.1$ or $\mathrm{I}^{2}>50 \%$, it was regarded as heterogeneous, and the source of heterogeneity was identified. If the heterogeneity was large, a random effects model was used, whereas if the heterogeneity was small, a fixed effects model was used. Subgroup analysis was also used to identify the source of heterogeneity. It was based on subject characteristics (postmenopausal women, unclassified women, men or adults) and lipid-lowering drugs (taking or not taking) to do subgroup metaanalysis. If the heterogeneity was significantly reduced, the characteristics were the source of heterogeneity. Of note, if there was only one study in one subgroup, the result was not listed. Egger's test was conducted using Stata software to quantitatively evaluate publication bias. If $\mathrm{P}>0.05$, publication bias was considered non-existent.

\section{Results}

\subsection{Literature search results and basic characteristics of the included literature}

We retrieved 6,680, 11,899, and 2,476 articles from PubMed, Embase, and Cochrane libraries, respectively. Therefore, a total of 21,055 articles were imported into Endnote to manage the references. A stepwise screening was performed according to a previous method (Fig. S1). A total of 12 studies were finally included that involved 12,395 subjects. Among them, there were 8 osteopenia studies and 12 osteoporosis studies. The basic characteristics of included studies were shown in Table. 


\begin{tabular}{|c|c|c|c|c|c|c|c|c|c|c|}
\hline \multirow[t]{2}{*}{ First author } & \multirow[t]{2}{*}{ Year } & \multirow[t]{2}{*}{ Country } & \multirow[t]{2}{*}{ Age } & \multirow[t]{2}{*}{ Sex } & \multirow[t]{2}{*}{ Subjects } & \multirow{2}{*}{$\begin{array}{l}\text { Sample } \\
\text { size }\end{array}$} & \multirow{2}{*}{$\begin{array}{l}\text { NOS } \\
\text { score }\end{array}$} & \multirow{2}{*}{$\begin{array}{l}\text { Lipid- } \\
\text { lowering } \\
\text { drugs }\end{array}$} & \multicolumn{2}{|l|}{ Event } \\
\hline & & & & & & & & & Osteopenia & OP \\
\hline Alay ${ }^{[9]}$ & 2020 & Turkey & $53.9 \pm 6.7$ & $\mathrm{~F}$ & Postmenopausal & 452 & 6 & $\sqrt{ }$ & $\sqrt{ }$ & $\sqrt{ }$ \\
\hline Aleksandar ${ }^{[10]}$ & 2012 & Serbia & $57.0 \pm 4.8$ & $\mathrm{~F}$ & Postmenopausal & 300 & 6 & $\sqrt{ }$ & $\sqrt{ }$ & $\sqrt{ }$ \\
\hline Arikan $^{[11]}$ & 2011 & Turkey & $54.7 \pm 8.8$ & $\mathrm{~F}$ & Postmenopausal & 107 & 7 & $\sqrt{ }$ & $\sqrt{ }$ & $\sqrt{ }$ \\
\hline Bijelic ${ }^{[13]}$ & 2016 & Herzegovina & About 63 & $\mathrm{~F}$ & Postmenopausal & 200 & 7 & & & $\sqrt{ }$ \\
\hline $\mathrm{Gu}^{[6]}(1)$ & 2019 & China & $53.5 \pm 9.0$ & M & Men & 2,830 & 7 & $\sqrt{ }$ & $\sqrt{ }$ & $\sqrt{ }$ \\
\hline Gu (2) & 2019 & China & $52.3 \pm 8.9$ & $\mathrm{~F}$ & $\begin{array}{l}\text { Unclassified } \\
\text { women }\end{array}$ & 5.754 & 7 & & & \\
\hline $\operatorname{Han}^{[19]}$ & 2017 & China & $59.9 \pm 11.0$ & $\begin{array}{l}\mathrm{M} \\
\mathrm{F}\end{array}$ & Adults & 674 & 8 & $\sqrt{ }$ & $\sqrt{ }$ & $\sqrt{ }$ \\
\hline Huang ${ }^{[20]}$ & 2016 & China & $60.6 \pm 11.9$ & $\mathrm{~F}$ & Postmenopausal & 233 & 7 & $\sqrt{ }$ & $\sqrt{ }$ & $\sqrt{ }$ \\
\hline $\mathrm{Li}^{[8]}$ & 2015 & China & $62.3 \pm 6.2$ & $\mathrm{~F}$ & Postmenopausal & 790 & 6 & & & $\sqrt{ }$ \\
\hline Pliatsika ${ }^{[27]}$ & 2012 & Greece & $53.0 \pm 5.7$ & $\mathrm{~F}$ & Postmenopausal & 591 & 6 & $\sqrt{ }$ & $\sqrt{ }$ & $\sqrt{ }$ \\
\hline Qi[29] & 2016 & China & $56.6 \pm 4.9$ & $\mathrm{~F}$ & Postmenopausal & 260 & 7 & $\sqrt{ }$ & $\sqrt{ }$ & $\sqrt{ }$ \\
\hline Sivas ${ }^{[31]}$ & 2009 & Turkey & $60.0 \pm 6.0$ & $\mathrm{~F}$ & Postmenopausal & 107 & 6 & & & $\sqrt{ }$ \\
\hline Verit $^{[34]}$ & 2007 & Turkey & $54.0 \pm 3.6$ & $\mathrm{~F}$ & Postmenopausal & 97 & 6 & & & \\
\hline
\end{tabular}

Table

Basic characteristics of included studies.

\subsection{Quality assessment}

According to the NOS form, we systematically evaluated the quality of the included articles. Six articles scored 6 points, 5 articles scored 7 points, and 1 article scored 8 points. Overall, the quality of the included literature was acceptable.

\subsection{Lipid levels in patients with osteopenia}

\subsubsection{TC}

There were 8 studies ( 9,747 subjects) that measured TC levels in patients with osteopenia. Using a random effects model, the total effect amount was $\mathrm{MD}=0.08 \mathrm{mmol} / \mathrm{L}\left(95 \% \mathrm{Cl}:-0.06,0.22 ; \mathrm{l}^{2}=87 \% ; \mathrm{P}<0.00001\right)$, which indicated large heterogeneity (Fig. $\left.1 \mathrm{~A}\right)$. A subgroup analysis was performed according to the characteristics of the subjects: the postmenopausal women subgroup had a MD = $0.05 \mathrm{mmol} / \mathrm{L}\left(95 \% \mathrm{Cl}:-0.25,0.36 ; \mathrm{I}^{2}=87 \%\right.$; and $\left.\mathrm{P}<0.00001\right)$ (Fig. 1B). Another subgroup analysis based on the lipid-lowering drugs: no lipid-lowering drugs subgroup had a MD $=0.11 \mathrm{mmol} / \mathrm{L}\left(95 \% \mathrm{Cl}:-0.03,0.25 ; \mathrm{I}^{2}=21 \% ; \mathrm{P}=0.36\right)$; the other subgroup had a $\mathrm{MD}=$ $0.08 \mathrm{mmol} / \mathrm{L}\left(95 \% \mathrm{Cl}:-0.12,0.27 ; \mathrm{I}^{2}=91 \% ; \mathrm{P}<0.00001\right)$ (Fig. 1C). The results indicated that there was no difference in TC levels between the osteopenia group and the normal group in subjects without taking drugs. There was no publication bias because $\mathrm{P}=0.969$, according to Egger's test (Fig.S2A).

\subsubsection{TG}

There were 7 studies (9,471 subjects) that measured TG levels in patients with osteopenia. Using a random effects model, the MD = $0.04 \mathrm{mmol} / \mathrm{L}\left(95 \% \mathrm{Cl}:-0.05,0.12 ; \mathrm{l}^{2}=68 \% ; \mathrm{P}=0.003\right)$, which indicated large heterogeneity (Fig. $\left.2 \mathrm{~A}\right)$. Subgroup analyses were then performed. The postmenopausal women subgroup had a $\mathrm{MD}=0.00 \mathrm{mmol} / \mathrm{L}\left(95 \% \mathrm{Cl}:-0.18,0.19 ; \mathrm{I}^{2}=81 \% ; \mathrm{P}=0.0001\right)$ (Fig. 2B). The no lipid lowering drugs subgroup had a MD $=-0.01 \mathrm{mmol} / \mathrm{L}\left(95 \% \mathrm{Cl}:-0.09,0.07 ; \mathrm{I}^{2}=6 \% ; \mathrm{P}=0.34\right)$, the other subgroup had a $\mathrm{MD}=$ 
$0.07 \mathrm{mmol} / \mathrm{L}\left(95 \% \mathrm{Cl}: 0.03,0.12 ; \mathrm{I}^{2}=76 \% ; \mathrm{P}=0.002\right)$ (Fig. $2 \mathrm{C}$ ). Therefore, no difference in TG levels existed between the osteopenia group and the control group in subjects without taking lipid-lowering drugs. $P=0.817$ in Egger's test, which indicated that there was no publication bias (Fig. S2B).

\subsubsection{HDL-C}

A total of 6 studies (9,360 subjects) measured HDL-C levels in patients with osteopenia. The total effect amount was MD $=0.01 \mathrm{mmol} / \mathrm{L}$ (95\% Cl: $\left.-0.01,0.02 ; I^{2}=38 \% ; P=0.14\right)$ in the fixed effects model (Fig. 3). There was no difference in HDL-C levels between the osteopenia group and the control group. We found that $\mathrm{P}=0.734$ in Egger's test, indicating that there was no publication bias (Fig. S2C).

\subsubsection{LDL-C}

Six studies (9,420 subjects) determined LDL-C levels in patients with osteopenia. A random effects model was used, and the MD = $0.04 \mathrm{mmol} / \mathrm{L}\left(95 \% \mathrm{Cl}:-0.03,0.12 ; \mathrm{I}^{2}=66 \% ; \mathrm{P}=0.007\right)(\mathrm{Fig} .4 \mathrm{~A})$. Subgroup analyses were performed to identify the source of heterogeneity. In the postmenopausal women subgroup, the $\mathrm{MD}=0.02 \mathrm{mmol} / \mathrm{L}\left(95 \% \mathrm{Cl}:-0.09,0.13 ; \mathrm{I}^{2}=0 \% ; \mathrm{P}=0.74\right)$ (Fig. 4B). In subjects without lipid-lowering drugs, the $\mathrm{MD}=0.10 \mathrm{mmol} / \mathrm{L}\left(95 \% \mathrm{Cl}: 0.00,0.19 ; \mathrm{I}^{2}=0 \% ; \mathrm{P}=0.74\right) ;$ In subjects who were taking drugs, the $\mathrm{MD}=0.01 \mathrm{mmol} / \mathrm{L}\left(95 \% \mathrm{Cl}:-0.10,0.12 ; \mathrm{I}^{2}=81 \% ; \mathrm{P}=0.001\right)$ (Fig. $\left.4 \mathrm{C}\right)$. There was no difference in LDL-C levels between the two groups in postmenopausal women or subjects without lipid-lowering drugs. There was no publication bias because $\mathrm{P}=0.639$ in Egger's test (Fig. S2D).

\subsection{Lipid levels in patients with osteoporosis}

\subsubsection{TC}

A total of 12 studies ( 7,870 subjects) measured TC levels in patients with osteoporosis. Using a random effects model, the MD was $0.20 \mathrm{mmol} / \mathrm{L}\left(95 \% \mathrm{Cl}:-0.04,0.43 ; \mathrm{I}^{2}=94 \% ; \mathrm{P}<0.00001\right)$, indicating large heterogeneity (Fig. S3A). A subgroup analysis was performed according to the characteristics of the subjects: postmenopausal women had a MD $=0.18 \mathrm{mmol} / \mathrm{L}\left(95 \% \mathrm{Cl}:-0.19,0.56 ; \mathrm{I}^{2}=95 \% ; \mathrm{P}<\right.$ 0.00001) (Fig. S3B). The other subgroup analysis was performed based on whether or not taking lipid-lowering drugs. Subjects who were not taking lipid-lowering drugs had a $\mathrm{MD}=0.20 \mathrm{mmol} / \mathrm{L}\left(95 \% \mathrm{Cl}:-0.11,0.41 ; \mathrm{I}^{2}=79 \% ; \mathrm{P}<0.0001\right)$, In others, the $\mathrm{MD}=0.18 \mathrm{mmol} / \mathrm{L}$ (95\%Cl: $\left.-0.29,0.65 ; I^{2}=97 \% ; P<0.00001\right)$ (Fig. S3C). The results showed neither characteristics of the subjects or lipid-lowering drugs was not the source of heterogeneity. There was no publication bias because $\mathrm{P}=0.731$ in Egger's test (Fig. S4A).

\subsubsection{TG}

Eleven articles involving 7,597 subjects reported TG levels in patients with osteoporosis. The total effect amount was $\mathrm{MD}=0.02 \mathrm{mmol} / \mathrm{L}$ (95\% Cl: $\left.-0.10,0.14 ; I^{2}=79 \% ; P<0.00001\right)$ in a random effects model, which indicated large heterogeneity (Fig. 5A). The postmenopausal women subgroup had a $\mathrm{MD}=0.01 \mathrm{mmol} / \mathrm{L}\left(95 \% \mathrm{Cl}:-0.18,0.11 ; \mathrm{I}^{2}=83 \% ; \mathrm{P}<0.00001\right)$ (Fig. $\left.5 \mathrm{~B}\right)$. The subjects without taking lipid-lowering drugs subgroup had a $M D=-0.04 \mathrm{mmol} / \mathrm{L}\left(95 \% \mathrm{Cl}:-0.14,0.07 ; \mathrm{I}^{2}=49 \% ; \mathrm{P}=0.07\right)$; In the other subgroup, the $\mathrm{MD}=$ $0.10 \mathrm{mmol} / \mathrm{L}\left(95 \% \mathrm{Cl}:-0.14,0.33 ; \mathrm{I}^{2}=88 \% ; \mathrm{P}<0.00001\right)$ (Fig. $\left.5 \mathrm{C}\right)$. There was no difference in TG between the two groups in subjects who were not taking lipid-lowering drugs. We found that $\mathrm{P}=0.657$ in Egger's test, suggesting that there was no publication bias (Fig. S4B).

\subsubsection{HDL-C}

Ten studies involving 7,424 subjects measured HDL-C levels in patients with osteoporosis. The MD was $0.05 \mathrm{mmol} / \mathrm{L}(95 \% \mathrm{Cl}$ : 0.03, 0.07; $\left.\mathrm{I}^{2}=31 \% ; \mathrm{P}=0.15\right)$ in the fixed effect model, which indicated that HDL-C levels were higher in the osteoporosis group than in the control group (Fig. 6). $P=0.627$ in Egger's test, which indicated that there was some publication bias (Fig. S4C).

\subsubsection{LDL-C}

A total of 10 studies (7,512 subjects) reported LDL-C levels in patients with osteoporosis. The total effect amount was MD = $0.23 \mathrm{mmol} / \mathrm{L}\left(95 \% \mathrm{Cl}: 0.07,0.39 ; \mathrm{I}^{2}=89 \%\right.$; and $\left.\mathrm{P}<0.00001\right)$, indicating large heterogeneity (Fig. S5A). Therefore, subgroup analyses were performed. Postmenopausal women had a MD $=0.29 \mathrm{mmol} / \mathrm{L}\left(95 \% \mathrm{Cl}:-0.02,0.59 ; \mathrm{I}^{2}=91 \% ; \mathrm{P}<0.00001\right)$ based the characteristics of the subjects (Fig. S5B). Subjects who did not took lipid-lowering drugs had a MD =0.16 mmol/L (95\%Cl: 0.02,0.31; $\left.\mathrm{I}^{2}=68 \% ; \mathrm{P}=0.005\right)$. In 
subjects who took drugs, the MD $=0.35 \mathrm{mmol} / \mathrm{L}\left(95 \% \mathrm{Cl}:-0.04,0.73 ; \mathrm{I}^{2}=96 \% ; \mathrm{P}<0.00001\right)$ (Fig. S5C). So the heterogeneity was not found. $P=0.452$ in Egger's test, indicating that there was no publication bias (Fig. S4D).

\section{Discussion}

We used the Egger's test to quantitatively evaluate publication bias. All P-values were $>0.05$, indicating that there was no publication bias. The quality of the included literature was evaluated by the NOS score, which were all above median level, indicating that the quality of the included literature was acceptable, and the results of the meta-analysis were relatively credible.

This meta-analysis involved 12 studies and a total of 12,395 subjects. The studies included two events (osteopenia and OP) and four indicators (TC, TG, HDL-C, and LDL-C). The larger number of subjects strived for a stable result. Some results in this meta-analysis were heterogeneous, so we performed subgroup analyses based on two factors. The first factor was the characteristics of the subjects, which may be due to the actions of hormone. Postmenopausal women are more prone to OP because of lack of estrogen protection. The other factor was whether or not take lipid-lowering drugs, because it affects blood lipid levels. Even if subgroup analyses were conducted, some sources of heterogeneity were still not found, and we considered the possible reason was mixed effects of multiple confounding factors.

Trimpou et al. ${ }^{[33]}$ observed the necrosis of the femoral head under an electron microscope and found that the number and size of fat cells were significantly increased, suggesting that hypercholesterolemia is an independent risk factor for osteoporotic fractures. A recent meta-analysis, including 33 studies (16 cohort studies, 7 case-control studies, and 10 randomized controlled trials) showed that statins reduced the risk of total and hip fractures. The use of statins has been associated with an increase in total hip BMD and lumbar spine and was found to increase the expression of bone formation markers, such as osteocalcin ${ }^{[42]}$.

The pathophysiological relationship between blood lipid levels and BMD remains unclear. Most studies report that eating a high-fat diet reduces bone strength, changes the microstructure of the cancellous bone compartment, and changes the bone marrow environment, and low-level inflammation may play a role in these processes ${ }^{[43]}$. TC and its metabolites have been reported to affect the functional activity of osteoblasts in vitro and in vivo ${ }^{[4]}$. Elevated serum lipids may cause bone blood vessels to accumulate in the subendothelial matrix and may inhibit the differentiation and mineralization of bone cells.

This study has some limitations. First, the overall heterogeneity of the meta-analysis results obtained in this study was large, and the source of heterogeneity according to subject characteristics or lipid-lowering drugs was not identified in some studies. Considering the number of included studies, the sources of heterogeneity may involve many aspects. Second, most of the participants included in this meta-analysis were postmenopausal women because there are limited studies on men. However, the male population is a group that needs our attention. We look forward to more individual studies on male OP to perform a future meta-analysis. Third, we included casecontrol studies with weaker levels of evidence. Long-term cohort studies are needed to determine the effects of elevated blood lipids on osteopenia, OP, and fractures.

\section{Conclusions}

In conclusion, there was no difference of TC, TG and LDL-C between osteopenia/OP group and control group in subjects who were not taking lipid-lowering drugs. HDL-C was elevated in OP group but not in osteopenia group in all subjects. In addition, no difference existed between osteopenia and control group in postmenopausal women. It reminds us that blood lipid levels should be controlled and maintained in an appropriate range to reduce the risk of osteopenia, or OP. In future, blood lipid levels can be grouped and incidence of osteopenia and OP could be obtained after long follow up, so results would be more powerful.

\section{Abbreviations}

BMD: bone mineral density, BMI: body mass index, HDL-C: high-density lipoprotein cholesterol, LDL-C: low-density lipoprotein cholesterol, MD: mean difference, TC: total cholesterol, TG: triglyceride, OP: osteoporosis, $95 \% \mathrm{Cl}$ : $95 \%$ confidence interval.

\section{Declarations}

\section{Ethics approval and consent to participate}


All analyses were based on previous published studies, thus no ethical approval and patient consent are required.

\section{Consent for publication}

Not applicable.

\section{Availability of data and materials}

The original data can be obtained by email request.

\section{Competing interests}

The authors declare that they have no competing interests.

\section{Funding}

This research did not receive any specific grant from funding agencies in the public, commercial, or not-for-profit sectors.

\section{Authors' Contributions}

ZH: Conceptualization, Methodology, Writing - original draft. SA, LY, QLC and ZC: Methodology, Software. SGY and RLP: Conceptualization, Writing - review \& editing. All authors read and approved the final manuscript.

\section{Acknowledgments}

We thank Melissa Crawford, PhD, from Liwen Bianji, Edanz Editing China (www.liwenbianji.cn/ac), for editing the English text of a draft of this manuscript.

\section{References}

1. Zhang Y, Chai Y, Pan X, Shen H, Wei X, Xie Y. Tai chi for treating osteopenia and primary osteoporosis: a meta-analysis and trial sequential analysis. Clin Interv Aging. 2019;14:91-104.

2. Bliuc, N.D.Nguyen, D.Alarkawi, T.V.Nguyen, J.A.Eisman, J.R.Center. Accelerated bone loss and increased post-fracture mortality in elderly women and men. Osteoporos Int. 2015;26:1331-1339.

3. Gerber LM, Bener A, Al-Ali HM, Hammoudeh M, Liu LQ, Verjee M. Bone mineral density in midlife women: the Study of Women's Health in Qatar. Climacteric. 2015;18:316-322.

4. Acar B, Ozay AC, Ozay OE, Okyay E, Sisman AR, Ozaksoy D. Evaluation of thyroid function status among postmenopausal women with and without osteoporosis. Int J Gynaecol Obstet. 2016;134:53-57.

5. Li Y, Hui M, Chang X, et al. BMI reduction and vitamin D insufficiency mediated osteoporosis and fragility fractures in patients at nutritional risk: a cross-sectional study. Eur J Clin Nutr. 2018;72:455-459.

6. Gu LJ, Lai XY, Wang YP, Zhang JM, Liu JP. A community-based study of the relationship between calcaneal bone mineral density and systemic parameters of blood glucose and lipids. Medicine (Baltimore). 2019;98:e16096.

7. Ersoy GS, Simsek EE, Vatansever D, Kasikci HO, Keser B, Sakin O. Lipid profile and plasma atherogenic index in postmenopausal osteoporosis. North Clin Istanb. 2017;4:237-241.

8. Li S, Guo H, Liu Y, et al. Relationships of serum lipid profiles and bone mineral density in postmenopausal Chinese women. Clin Endocrinol (Oxf). 2015;82:53-58.

9. Alay I, Kaya C, Cengiz H, Yildiz S, Ekin M, Yasar L. The relation of body mass index, menopausal symptoms, and lipid profile with bone mineral density in postmenopausal women. Taiwan J Obstet Gynecol. 2020;59:61-66. 
10. Dimic A, Popovic MR, Tasic I, et al. Relation between bone density and certain parameters of lipid status in postmenopausal women. Cent Eur J Med. 2012;7:642-649.

11. Arikan DC, Coskun A, Ozer A, Kilinc M, Atalay F, Arikan T. Plasma selenium, zinc, copper and lipid levels in postmenopausal Turkish women and their relation with osteoporosis. Biol Trace Elem Res. 2011;144:407-417.

12. Bagger YZ, Rasmussen HB, Alexandersen P, Werge T, Christiansen C, Tankó LB. Links between cardiovascular disease and osteoporosis in postmenopausal women: Serum lipids or atherosclerosis per se? Osteoporos Int. 2007;18:505-512.

13. Bijelic R, Balaban J, Milicevic S. Correlation of the Lipid Profile, BMI and Bone Mineral Density in Postmenopausal Women. Mater Sociomed. 2016;28:412-415.

14. Chen Z, Zhao GH, Zhang YK, Shen GS, Xu YJ, Xu NW. Research on the correlation of diabetes mellitus complicated with osteoporosis with lipid metabolism, adipokines and inflammatory factors and its regression analysis. Eur Rev Med Pharmacol Sci. 2017;21:3900-3905.

15. Demir B, Haberal A, Geyik P, et al. Identification of the risk factors for osteoporosis among postmenopausal women. Maturitas. 2008;60:253-256.

16. Filardi T, Carnevale V, Massoud R, et al. High serum osteopontin levels are associated with prevalent fractures and worse lipid profile in post-menopausal women with type 2 diabetes. J Endocrinol Invest. 2019;42:295-301.

17. Hajsadeghi S, Khamseh ME, Larijani B, et al. Bone mineral density and coronary atherosclerosis. J Saudi Heart Assoc. 2011;23:143146.

18. Hamilton EJ, Davis WA, Bruce DG, Davis TME. Risk and associates of incident hip fracture in type 1 diabetes: The Fremantle Diabetes Study. Diabetes Res Clin Pract. 2017;134:153-160.

19. Han W, Bai X, Wang N, Han L, Sun X, Chen X. Association between lumbar bone mineral density and serum uric acid in postmenopausal women: a cross-sectional study of healthy Chinese population. Arch Osteoporos. 2017;12:50.

20. Huang C, Li S. Association of blood neutrophil lymphocyte ratio in the patients with postmenopausal osteoporosis. Pak J Med Sci. 2016;32:762-765.

21. Kim KC, Shin DH, Lee SY, Im JA, Lee DC. Relation between obesity and bone mineral density and vertebral fractures in Korean postmenopausal women. Yonsei Med J. 2010;51:857-863.

22. Lampropoulos CE, Kalamara P, Konsta M, et al. Osteoporosis and vascular calcification in postmenopausal women: a crosssectional study. Climacteric. 2016;19:303-307.

23. Lee SN, Cho JY, Eun YM, Song SW, Moon KW. Associations between osteoporosis and coronary artery disease in postmenopausal women. Climacteric. 2016;19:458-462.

24. Li XS, Zhang JR, Meng SY, Li Y, Wang RT. Mean platelet volume is negatively associated with bone mineral density in postmenopausal women. J Bone Miner Metab. 2012;30:660-665.

25. Liang DK, Bai XJ, Wu B, et al. Associations between bone mineral density and subclinical atherosclerosis: A cross-sectional study of a Chinese population. J Clin Endocrinol Metab. 2014;99:469-477.

26. Lipovetzki Y, Zandman-Goddard G, Feldbrin Z, Shargorodsky M. Elevated ferritin and circulating osteoprotegerin levels as independent predictors of hip fracture in postmenopausal women admitted for fragility fracture: time for new screening strategies? Immunol Res. 2017;65:423-427.

27. Pliatsika P, Antoniou A, Alexandrou A, et al. Serum lipid levels and bone mineral density in Greek postmenopausal women. Gynecol Endocrinol. 2012;28:655-660.

28. Poli A, Bruschi F, Cesana B, Rossi M, Paoletti R, Crosignani PG. Plasma low-density lipoprotein cholesterol and bone mass densitometry in postmenopausal women. Obstet Gynecol. 2003;102:922-926.

29. Qi H, Bao J, An G, et al. Association between the metabolome and bone mineral density in pre- and post-menopausal Chinese women using GC-MS. Mol Biosyst. 2016;12:2265-2275.

30. Saoji R, Das RS, Desai M, et al. Association of high-density lipoprotein, triglycerides, and homocysteine with bone mineral density in young Indian tribal women. Arch Osteoporos. 2018;13:108.

31. Sivas F, Alemdaroğlu E, Elverici E, Kuluğ T, Özoran K. Serum lipid profile: Its relationship with osteoporotic vertebrae fractures and bone mineral density in Turkish postmenopausal women. Rheumatol Int. 2009;29:885-890.

32. Sumino H, Ichikawa S, Kasama S, et al. Relationship between carotid atherosclerosis and lumbar spine bone mineral density in postmenopausal Women. Hypertens Res. 2008;31:1191-1197.

Page 8/14 
33. Trimpou P, Odén A, Simonsson T, Wilhelmsen L, Landin-Wilhelmsen K. High serum total cholesterol is a long-term cause of osteoporotic fracture. Osteoporos Int. 2011;22:1615-1620.

34. Verit FF, Celik H, Yazgan P, Erel O, Geyikli I. Paraoxonase-1 activity as a marker of atherosclerosis is not associated with low bone mineral density in healthy postmenopausal women. Arch Gynecol Obstet. 2007;275:353-359.

35. Wang RT, Liu HT, Zhao YL, et al. Bone mineral density is associated with left ventricular diastolic function in men with type 2 diabetes. Diabetes Metab. 2016;42:256-262.

36. Wang Y, Dai J, Zhong W, Hu C, Lu S, Chai Y. Association between serum cholesterol level and osteoporotic fractures. Front Endocrinol (Lausanne). 2018;9:30.

37. Wu DY, Qiao D, Zhang X, et al. Lipid profiles as potential mediators linking body mass index to osteoporosis among Chinese adults: the Henan Rural Cohort Study. Osteoporos Int. 2019;30:1413-1422.

38. Xiao W, Gong C, Liu X, et al. Association of P2X7R gene with serum lipid profiles in Chinese postmenopausal women with osteoporosis. Climacteric. 2019;22:498-506.

39. Yamaguchi T, Sugimoto T, Yano S, et al. Plasma lipids and osteoporosis in postmenopausal women. Endocr J. 2002;49:211-217.

40. Yamauchi M, Yamaguchi T, Nawata K, et al. Increased low-density lipoprotein cholesterol level is associated with non-vertebral fractures in postmenopausal women. Endocrine. 2015;48:279-286.

41. Yoldemir T, Yavuz DG. Association of serum paraoxonase concentration with serum lipid levels and bone mineral density measurements in early postmenopausal women. Climacteric. 2015;18:405-410.

42. An T, Hao J, Sun S, et al. Efficacy of statins for osteoporosis: a systematic review and meta-analysis. Osteoporos Int. 2017;28:47-57.

43. Chan MY, Nguyen ND, Center JR, Eisman JA, Nguyen TV. Absolute fracture-risk prediction by a combination of calcaneal quantitative ultrasound and bone mineral density. Calcif Tissue Int. 2012;90(2):128-136.

44. Parhami F, Garfinkel A, Demer LL. Role of lipids in osteoporosis. Arterioscler Thromb Vasc Biol. 2000;20:2346-2348.

\section{Figures}




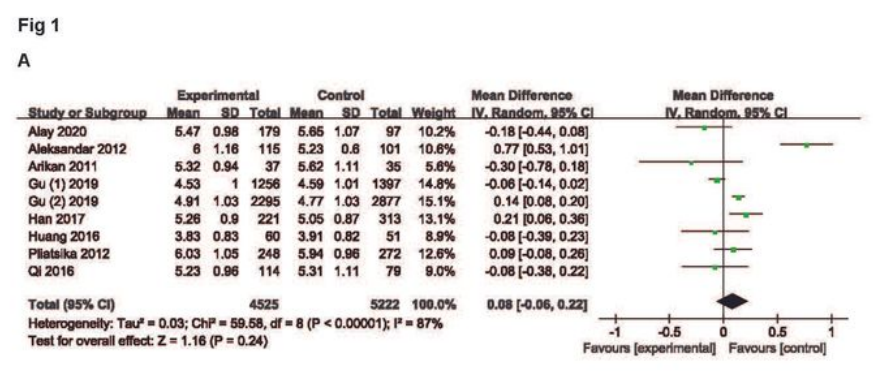

B

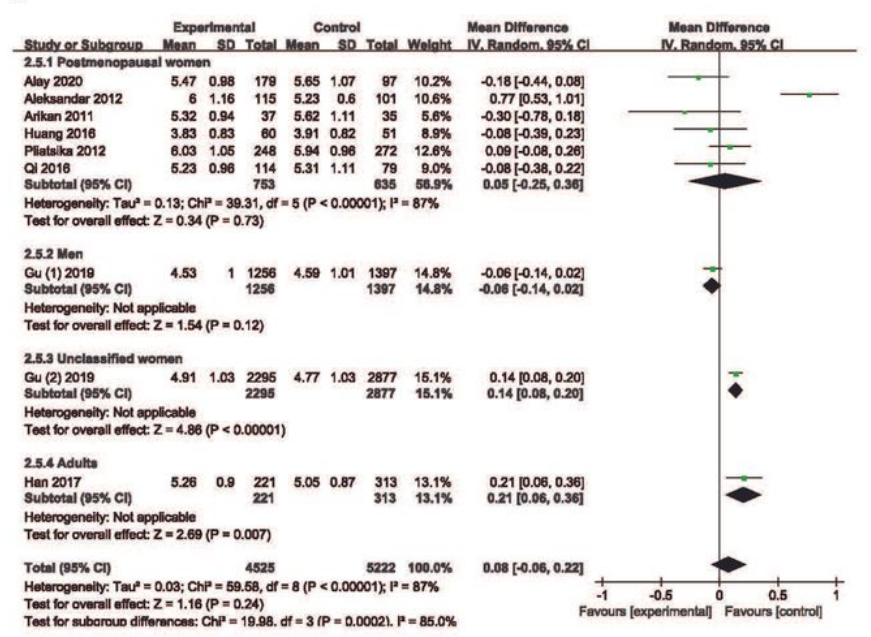

C

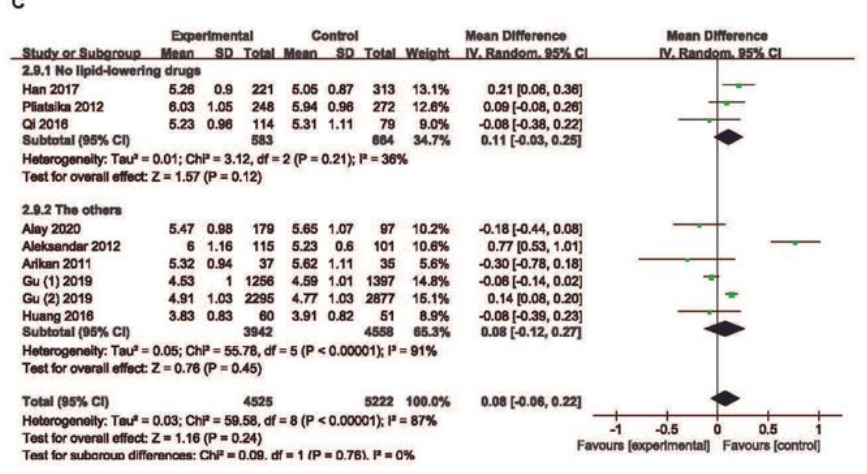

\section{Figure 1}

Forest plot comparing the total cholesterol level of the control and osteopenia groups. (A) total subjects; (B) subgroup analysis based on subjects' characteristics; (C) subgroup analysis based on lipid-lowering drugs. 


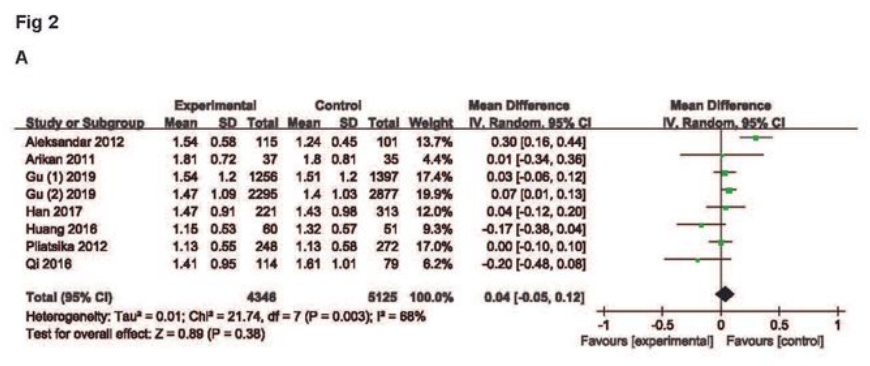

B

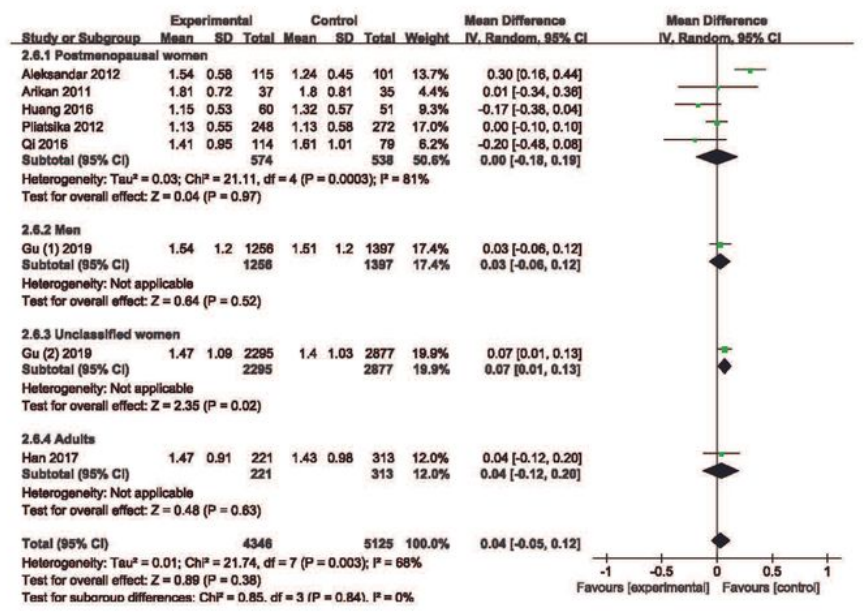

c

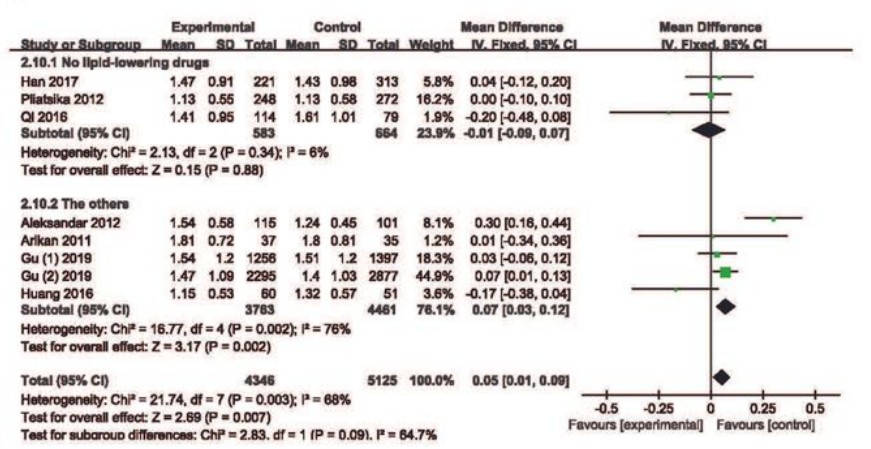

Figure 2

Forest plot comparing the triglyceride level of the control and osteopenia groups. (A) total subjects; (B) subgroup analysis based on subjects' characteristics; (C) subgroup analysis based on lipid-lowering drugs.

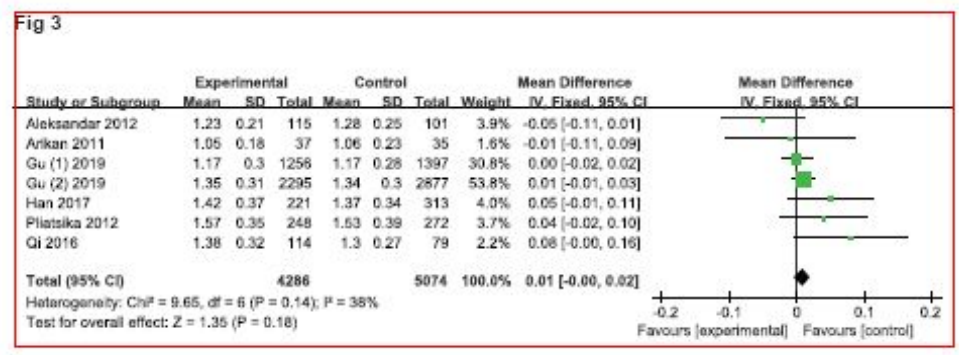

\section{Figure 3}

Forest plot comparing the high-density lipoprotein cholesterol level of the control and osteopenia groups. 


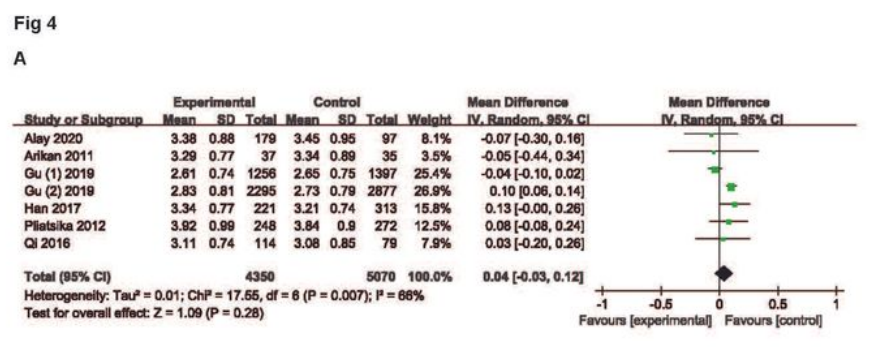

B

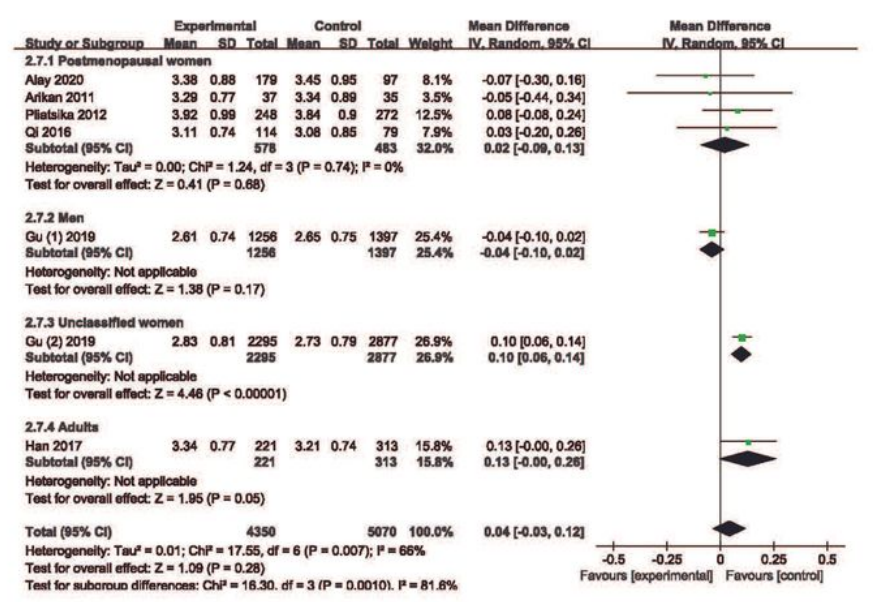

C

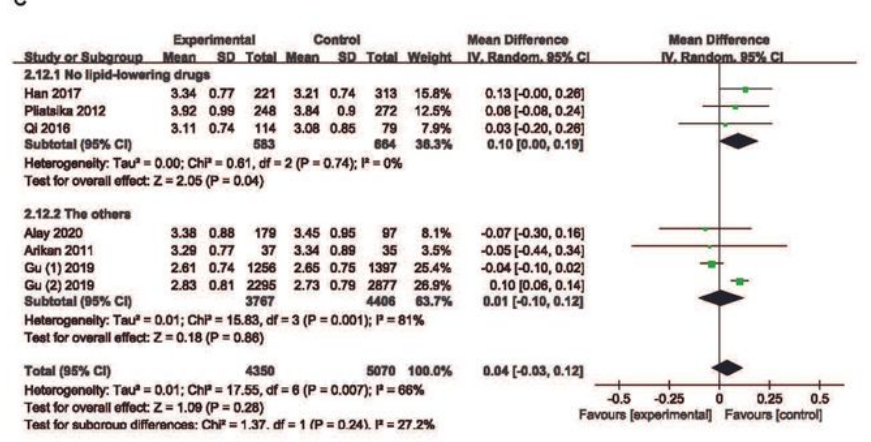

\section{Figure 4}

Forest plot comparing the low-density lipoprotein cholesterol level of the control and osteopenia groups. (A) total subjects; (B) subgroup analysis based on subjects' characteristics; (C) subgroup analysis based on lipid-lowering drugs. 


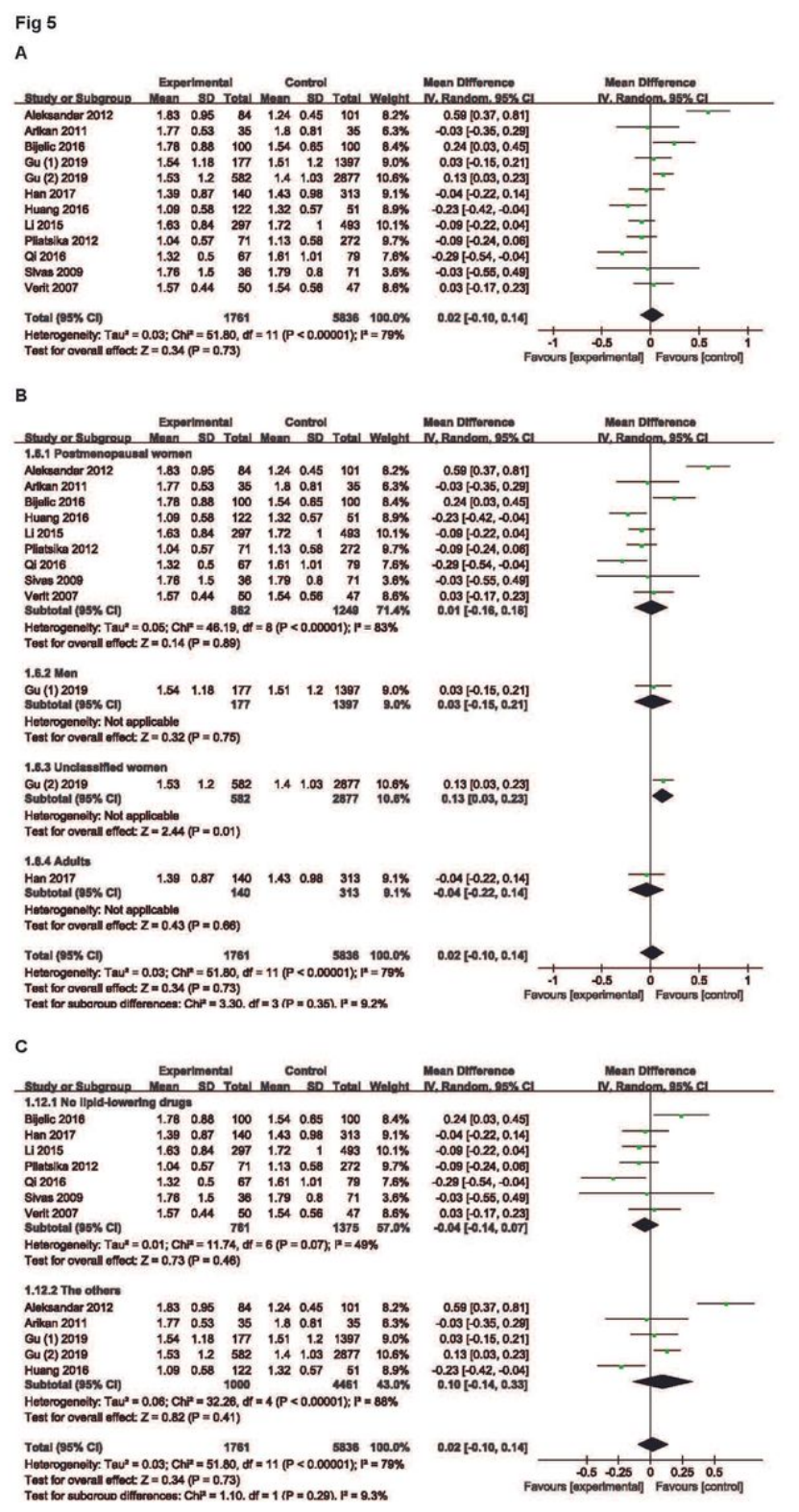

\section{Figure 5}

Forest plot comparing the triglyceride level of the control and osteoporosis groups. (A) total subjects; (B) subgroup analysis based on subjects' characteristics; (C) subgroup analysis based on lipid-lowering drugs.

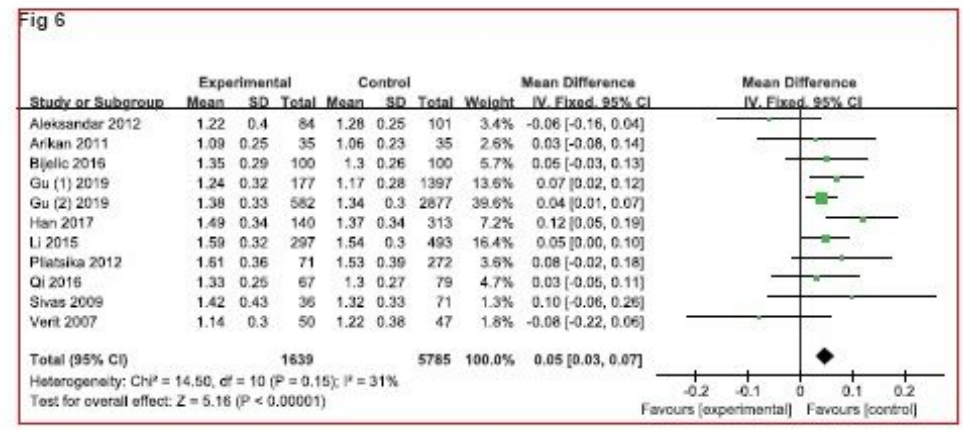

\section{Figure 6}

Forest plot comparing the high-density lipoprotein cholesterol level of the control and osteoporosis groups. 


\section{Supplementary Files}

This is a list of supplementary files associated with this preprint. Click to download.

- figures3.pdf

- supplementarymaterial1.docx

- supplementarymaterial2.docx

- languageeditingcertificate.pdf

- figureS5.pdf

- PRISMAChecklist.doc

- figureS1.pdf

- figures2.pdf

- figures4.pdf 